\title{
Systemic Lupus Erythematosus, Osteoporosis, and Fractures
}
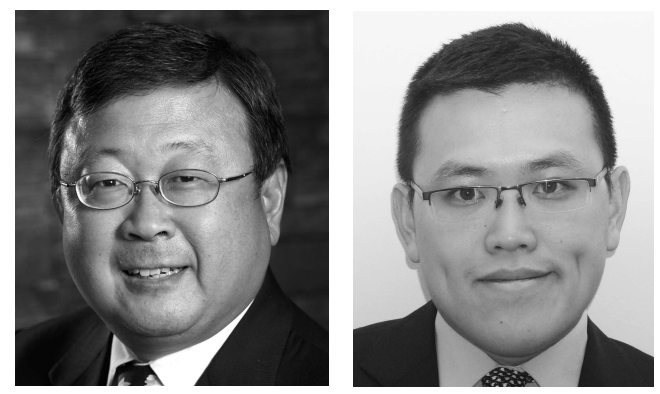

Osteoporosis is a common yet less-recognized complication of systemic lupus erythematosus (SLE) that has been brought to our attention by Zhu, et al's article in this issue of The Journal ${ }^{1}$. Recent studies, however, have highlighted the high prevalence of fractures in a relatively young population of women suffering from SLE SL, $, 3,4,5,6,7$. There have been many studies reporting different results. This might be explained by the complex relationship between SLE, complications of the disease itself or its treatment, duration of disease, bone loss, and fractures. Indeed the systemic inflammation associated with SLE and the resultant end-organ damage may all play a role re, $^{1,2,3}$. Combine this with the traditional risk factors for fracture and it is easy to understand why the study of osteoporosis and fractures in SLE is complex.

Confounders include active inflammation and treatment of inflammation with glucocorticoids ${ }^{1,2,3}$, menopausal status, and disease-associated complications such as renal bone disease and neuropsychiatric disease ${ }^{3}$. Other non-SLE risk factors including age, medications such as selective serotonin receptor inhibitors (SSRI) and possibly proton pump inhibitors (PPI) may all confound the relationship between SLE and fractures. The effect of treatment with bone-active drugs to prevent bone loss and fractures must also be taken into consideration in studies of SLE.

\section{Risk Factors}

Inflammation. There is a well-recognized association between inflammatory diseases, bone loss, and fractures. The classic example is rheumatoid arthritis. Other conditions such as inflammatory bowel and lung disease are also associated with increased fracture risk. Tumor necrosis factor- $\alpha$, interleukin 1 (IL-1), and IL-6 are well known activators of osteoclasts, leading to increased bone turnover and fractures ${ }^{8}$.

Renal disease. Of particular importance is the presence of renal disease in a large proportion of individuals with SLE. Renal disease is associated with fractures and osteoporosis, with greater renal dysfunction resulting in greater risk ${ }^{9}$. Even those with moderate chronic kidney disease have abnormalities in bone metabolism that predispose to bone loss and fractures.

Neurologic disease. Those with neurologic disease are often predisposed to falls and if their neuropsychiatric disease manifests as seizures and resultant falls, the risk of fractures increases. In those with neuropsychiatric SLE, there is an increased risk ${ }^{3}$. In addition to seizures, the use of anticonvulsants may be associated with fractures ${ }^{10}$.

Medications. There are a number of commonly used medications that may affect fracture risk in patients with SLE.

Glucocorticoids. Glucocorticoids are a well-recognized cause of bone loss ${ }^{11}$. They affect both premenopausal and postmenopausal women as well as men. Glucocorticoids lead to early rapid bone loss with increased fracture risk occurring shortly after initiation of therapy. There are many factors contributing to the loss of bone and fractures including direct effects on osteoblasts, osteoclasts, and osteocytes and indirect effects on calcium absorption, renal handling of calcium, reduced gonadal hormones, and decreased neuromuscular function ${ }^{12}$.

SSRI. SSRI use is ubiquitous in general ${ }^{13}$ and is commonly used in those with SLE, particularly when they have neuropsychiatric disease. SSRI have been associated with increased fracture risk and the risk of fractures may be increased if they are used in combination with glucocorticoids ${ }^{14}$.

PPI. A number of studies including a metaanalysis have reported a modest association between PPI and fractures ${ }^{15}$, with 1 report suggesting that PPI may negate the beneficial effects seen with alendronate therapy ${ }^{16}$.

Other drugs that are associated with fractures and may be used in the SLE population include anticonvulsants ${ }^{10}$, and benzodiazepines ${ }^{17}$.

Menopause. Menopause and irregular menstrual cycles may

See BMD change in SLE, page 1990

Personal non-commercial use only. The Journal of Rheumatology Copyright @ 2014 . All rights reserved. 
confound the bone loss seen in SLE. With active disease there are many young women with menstrual irregularities that may contribute to bone loss. Fractures are seldom seen in young populations because their youth and general health are protective. However, in the SLE population, fractures occur even in this young age group. Bone loss in older women who have gone through menopause occurs as would be seen in any postmenopausal women.

\section{Treatment}

Treatment may be divided into that which controls SLE disease and that which directly targets osteoporosis. Given the pathophysiology of bone loss and fractures in SLE, intervention that results in reduction of inflammation, with the exception of glucocorticoids, and control of disease are likely of benefit in reducing bone loss and increasing mobility and overall health. In principle this may be important in reducing fracture risk. Therapy with demonstrated efficacy in osteoporosis and fracture prevention for the most part includes the use of bisphosphonates. While other therapies are available, their use has not been well reported in this population.

The strengths of the current study include the identification and characterization of SLE as well as the traditional risk factors for fracturing. SLE disease activity was well documented using SLE Disease Activity Index. The documentation of flares and the severity of the flare, new organ damage, and the prospective capture of medications including antifracture medications are unique to this study of SLE and bone disease. Further strengths are the duration of followup and the examination of traditional risk factors for fracture including bone mineral density (BMD) measurements, measurement of vitamin $\mathrm{D}$, and the documentation of the cumulative dose and duration of glucocorticoid use. Unfortunately, the sample size is still relatively small, and as a result, it is not possible to adjust for the many potential confounders that may be seen in those with SLE. The age distribution included younger individuals, as would be expected in SLE; however, $62.4 \%$ were older postmenopausal women. Unfortunately, because of the lack of a control group, the important effects of age could not be examined relative to bone loss that might normally be seen in those without SLE. The effects of menopause were studied; however, the incidence of menstrual irregularities was not reported in this study. Factors such as comorbid disease, frailty, and falls, which are confounders that tend to be seen in an older population, were not reported. Renal function and new renal disease was associated with larger declines in BMD than other new organ damage. What is apparent from this study and consistent with earlier studies is the negative effect that glucocorticoids have on bone in this population. The association of greater declines in BMD with disease flare, renal disease, and new organ damage are important findings; and the fact that osteoporosis therapy prevents bone loss is reassuring.

The discrepancies in fracture risk seen among the various studies of SLE may be explained by many of the different risk factors seen in different SLE populations, different study durations, designs (cross-sectional vs prospective cohorts), sample sizes, and primary outcome measures. To elucidate the association of SLE to fractures and osteoporosis, larger studies must be completed to be able to control for many of the confounders that make the study of fractures in SLE difficult. The current study contributes to the literature by increasing the growing body of evidence required to further understand the association among SLE, $\mathrm{BMD}$, and the potential for fractures.

\section{JONATHAN D. ADACHI, MD, FRCPC Professor;}

ARTHUR LAU, MD, FRCPC,

Clinical Scholar,

Department of Medicine,

Michael G. DeGroote School of Medicine, St. Joseph's Healthcare-McMaster University, Hamilton, Ontario, Canada.

Address correspondence to Dr. Adachi, St. Joseph's Hospital, 501-25 Charlton Ave. East, Hamilton, Ontario L8N 1Y2, Canada. E-mail: jd.adachi@sympatico.ca

\section{REFERENCES}

1. Zhu TY, Griffith JF, Au S-K, Tang X-L, Kwok AW, Leung PC, et al. Bone mineral density change in systemic lupus erythematosus: A five-year follow-up study. J Rheumatol 2014;41:1990-7.

2. Bultink IE, Lems WF, Kostense PJ, Dijkmans BA, Voskuyl AE. Prevalence of and risk factors for low bone mineral density and vertebral fractures in patients with systemic lupus erythematosus. Arthritis Rheum 2005;52:2044-50.

3. Bultink IE, Harvey NC, Lalmohamed A, Cooper C, Lems WF, van Staa TP, et al. Elevated risk of clinical fractures and associated risk factors in patients with systemic lupus erythematosus versus matched controls: a population-based study in the United Kingdom. Osteoporos Int 2014;25:1275-83.

4. Li EK, Tam LS, Griffith JF, Zhu TY, Li TK, Li M, et al. High prevalence of asymptomatic vertebral fractures in Chinese women with systemic lupus erythematosus. J Rheumatol 2009;36:1646-52.

5. Borba VZ, Matos PG, da Silva Viana PR, Fernandes A, Sato EI, Lazaretti-Castro M. High prevalence of vertebral deformity in premenopausal systemic lupus erythematosus patients. Lupus 2005;14:529-33

6. Mendoza-Pinto C, Garcia-Carrasco M, Sandoval-Cruz H, Muñoz-Guarneros M, Escárcega RO, Jiménez-Hernández M, et al. Risk factors of vertebral fractures in women with systemic lupus erythematosus. Clin Rheumatol 2009;28:579-85.

7. Ramsey-Goldman R, Dunn JE, Huang CF, Dunlop D, Rairie JE, Fitzgerald S, et al. Frequency of fractures in women with systemic lupus erythematosus: comparison with United States population data. Arthritis Rheum 1999;42:882-90.

8. Brennan FM, McInnes IB. Evidence that cytokines play a role in rheumatoid arthritis. J Clin Invest 2008;118:3537-45.

9. Ensrud KE, Lui LY, Taylor BC, Shlipak MG, Stone KL, Cauley JA, et al. Renal function and risk of hip and vertebral fractures in older women. Arch Intern Med 2007;167:133-9. 
10. Lee RH, Lyles KW, Colon-Emeric C. A review of the effect of anticonvulsant medications on bone mineral density and fracture risk. Am J Geriatr Pharmacother 2010;8:34-46.

11. Lekamwasam S, Adachi JD, Agnusdei D, Bilezikian J, Boonen S, Borgström F, et al, and the Joint IOF-ECTS GIO Guidelines Working Group. A framework for the development of guidelines for the management of glucocorticoid-induced osteoporosis. Osteoporos Int 2012;23:2257-76.

12. Canalis E, Mazziotti G, Giustina A, Bilezikian JP. Glucocorticoid-induced osteoporosis: pathophysiology and therapy. Osteoporos Int 2007;18:1319-28.

13. Eom C-S, Lee H-K, Ye S, Park SM, Cho K-H. Use of selective serotonin reuptake inhibitors and risk of fracture: a systematic review and meta-analysis. J Bone Miner Res 2012;27:1186-95.
14. Adachi JD, Lacroix AZ, Lindsay R, March L, Netenbolos JC, Pfleilschifter J, et al. Fracture patterns with selective serotonin receptor inhibitor, proton pump inhibitor and glucocorticoids use in GLOW [abstract]. Osteoporos Int 2014:25 Suppl: S119.

15. Yu EW, Bauer SR, Bain PA, Bauer DC. Proton pump inhibitors and risk of fractures: a meta-analysis of 11 international studies. Am J Med 2011;124:519-26.

16. Abrahamsen B, Eiken P, Eastell R. Proton pump inhibitor use and the antifracture efficacy of alendronate. Arch Intern Med 2011;171:998-1004.

17. Xing D, Ma XL, Ma JX, Wang J, Yang Y, Chen Y. Association between use of benzodiazepines and risk of fractures: a meta-analysis. Osteoporos Int 2014;25:105-20.

J Rheumatol 2014;41:1913-5; doi:10.3899/jrheum.140919 